07

\title{
Поверхностный тепловой интерфейс для мощных арсенид-галлиевых гетероструктурных полевых транзисторов
}

\author{
() А.Б. Пашковский, И.В. Куликова, В.Г. Лапин, В.М. Лукашин, Н.К. Приступчик, Л.В. Манченко, В.Г. Калина, \\ М.И. Лопин, А.Д. Закурдаев
}

АО НПП „ИСТОК“ им. Шокина,

141190 Фрязино, Московская обл., Россия

e-mail: solidstate10@mail.ru

(Поступило в Редакцию 26 сентября 2017 г.)

\begin{abstract}
Проведен теоретический анализ возможностей использования теплопроводящих покрытий для охлаждения мощных полевых транзисторов на основе гетероструктур с арсенид-галлиевой подложкой. При сохранении базовой технологии изготовления транзисторов и без дополнительных мер по уменьшению теплового сопротивления подложки введение дополнительного теплового интерфейса в виде диэлектрического теплопроводящего покрытия позволяет значительно уменьшить перегрев канала транзистора. В зависимости от толщины покрытия, конструкции транзистора и режима его работы перегрев канала может быть снижен в несколько раз.
\end{abstract}

DOI: $10.21883 /$ JTF.2019.02.47079.2493

\section{Введение}

Обеспечение приемлемого теплового режима работы является одной из основных задач при разработке элементной базы СВЧ-полупроводниковых устройств, в которых используются GaAs подложки. Примером таких приборов являются мощные НЕМТ-транзисторы на основе $\mathrm{AlGaAs} / \mathrm{InGaAs} / \mathrm{GaAs}$ гетероструктур. Одной из основных причин ограничения СВЧ мощности этих транзисторов является большое тепловое сопротивление подложки. Из-за относительно малой величины теплопроводности GaAs (по сравнению с нитридом галлия, карбидом кремния и некоторыми другими материалами), в мощных HEMT-транзисторах GaAs подложка дает основной вклад в тепловое сопротивление „канал теплоотводящее основание корпуса“. При увеличении толщины подложки, уменьшении расстояния между секциями транзистора (исток-затвор-сток) температура канала увеличивается, подвижность электронов уменьшается и, как следствие, уменьшаются ток стока, коэффициент усиления и выходная мощность.

В современных мощных монолитных СВЧ усилителях для повышения быстродействия нужно уменьшать расстояния между секциями транзистора. Это позволяет уменьшить паразитные емкости и фазовые набеги между секциями. Однако возможности уменьшения этих расстояний в мощных НЕМТ-транзисторах ограничены максимально допустимой температурой канала транзистора. Это связано с деградационными процессами, начало которых может наблюдаться при температуре канала, равной $150^{\circ} \mathrm{C}$. В настоящее время основным методом обеспечения приемлемой температуры канала таких транзисторов является уменьшение толщины GaAs подложки до 25-30 $\mu \mathrm{m}$ (рис. $1, a, b$ ). Это позволяет уменьшить тепловое сопротивление транзистора, но, в то же время приводит к ухудшению механической прочности конструкции. Поэтому для сохранения механической прочности транзистора снизу на подложку наращивают толстый слой золота $(\sim 30 \mu \mathrm{m})$, хотя этот слой также вносит свой вклад в тепловое сопротивление. Долгие годы удельная выходная мощность НЕМТ-транзисторов, работающих в коротковолновой части сантиметрового диапазона длин волн, из-за различных физических и технологических ограничений составляла величины порядка $1 \mathrm{~W} / \mathrm{mm}$. При КПД транзистора около 50\% примерно такая же мощность рассеивается в его канале. Отвод тепла через подложку успешно обеспечивал тепловой режим работы таких приборов. Появление НЕМТ-гетероструктур с донорно-акцепторным легированием [1-3] позволило увеличить выходную мощность СВЧ-транзисторов в разы, что вызвало необходимость усиления теплоотвода.

\section{Обеспечение дополнительного отвода тепла от канала транзистора}

Традиционным методом охлаждения является отвод тепла от канала в подложку и далее в корпус транзистора (отвод тепла вниз). Существует много способов улучшения традиционного теплоотвода, например, [4], но, как отмечалось выше, все они по сути дела связаны с уменьшением толщины подложки. Некоторые варианты таких конструкций [5-7] успешно используются в нитрид-галлиевых полевых транзисторах, где из-за высокой удельной выходной СВЧ-мощности хороший отвод тепла особенно важен. Для мощных арсенидгаллиевых НЕМТ-транзисторов применение подобных способов отвода тепла связано с введением дополнительных технологических операций, что вызывает проблемы, всегда сопутствующие изменениям конструкции и технологии изготовления прибора. И все равно уменьшение 


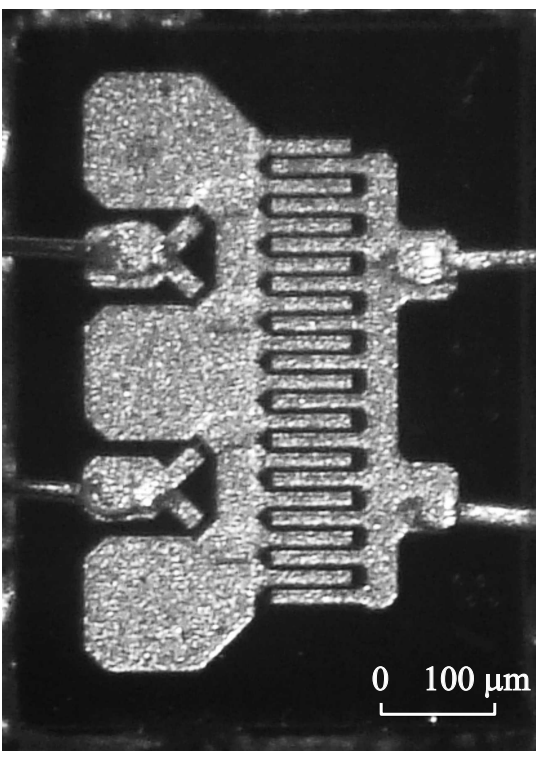

$a$

$b$
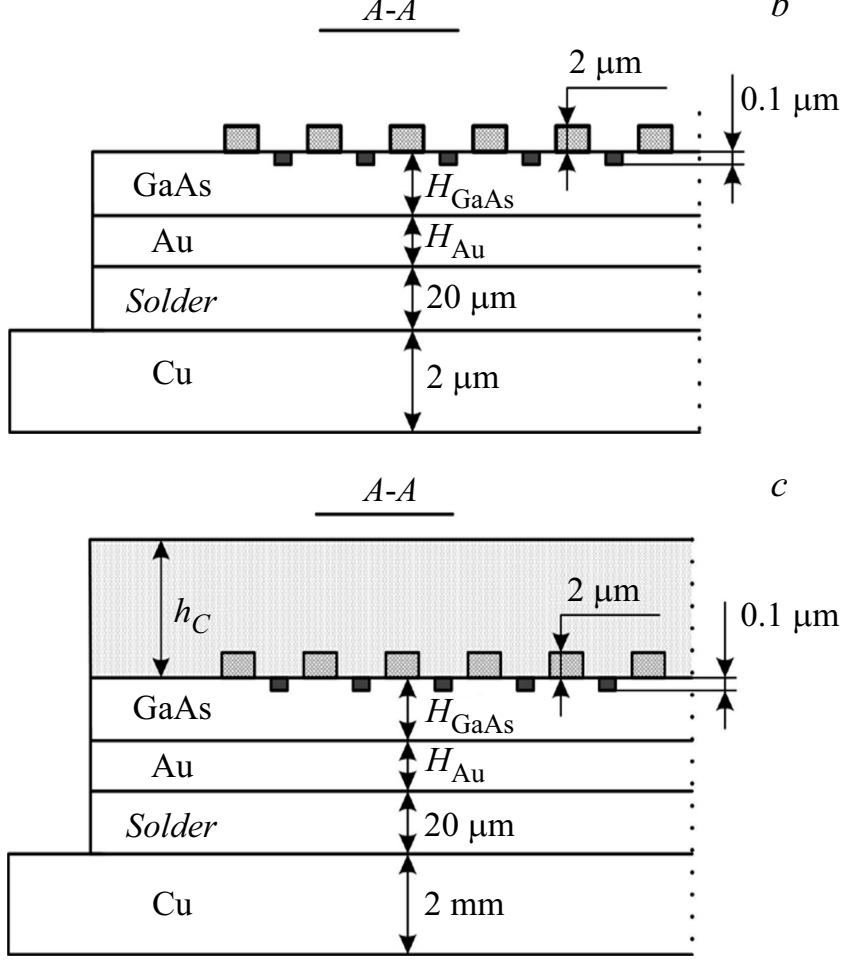

Pис. 1. Мощный СВЧ полевой транзистор типа на основе GaAs-гетероструктуры: $a-$ фотография полевого транзистора; $b-$ схематический упрощенный продольный разрез транзистора без теплового интерфейса; $c-$ схематический упрощенный продольный разрез транзистора с тепловым интерфейсом толщиной $h_{C}$.

толщины GaAs подложки HЕMТ-транзисторов до минимально возможной величины не решает кардинально задачу обеспечения хорошего теплоотвода.

В настоящей работе предлагается совершенно другой метод улучшения теплоотвода. Вместо того, чтобы пытаться непосредственно увеличить поток тепла из области максимального тепловыделения в канале транзистора вниз через подложку, предлагается дополнительно отводить тепло от канала вверх, через специальный тепловой интерфейс, выполненный в виде диэлектрического слоя, нанесенного на всю поверхность чипа транзистора (рис. 1,c). Особенности электронного транспорта в полевых транзисторах на GaAs-подложках приводят к сильной локализации области интенсивного тепловыделения в пределах площади расположения секций истоков, затворов и стоков $[8,9]$. Область интенсивного выделения тепла в канале намного меньше площади транзистора с контактными площадками и тем более меньше площади всего транзисторного чипа (рис. 1,a). Таким образом, основной отвод тепла из канала происходит на маленькой площади, и для улучшения теплоотвода необходимо увеличить площадь, с которой тепло через подложку уходит в корпус. Введение поверхностного теплового интерфейса на всей площади чипа транзистора как раз и решает эту задачу. Диэлектрический слой с высокой теплопроводностью на поверхности чипа обеспечивает дополнительную теплопередачу в подложку и далее в корпус. В этом случае для теплоотвода используется вся площадь контакта чипа транзистора с основанием корпуса. Поскольку площадь отвода потоков тепла на корпус существенно увеличивается, перегрев канала транзистора относительно корпуса значительно уменьшается.

Близкая идея - отводить тепло от канала в направлении, противоположном подложке, присутствует, например, в методе обратного монтажа кристаллов [10]. В этом случае эффективность отвода тепла невелика из-за того, что площадь области тепловыделения, а следовательно, и площадь области теплопередачи, остается слишком малой. Для мощных нитрид-галлиевых СВЧ транзисторов предложено развитие традиционного решения (отвода тепла вниз) в виде использования на подложке алмазоподобного покрытия (АПП) $[11,12]$. Анализ применимости АПП на подложке для $\mathrm{GaN}$ НЕМТ-транзисторов показывает, что для достижения ощутимых результатов в улучшении теплоотвода необходимо использовать АПП большой толщины, которое должно контактировать с достаточно тонкой подложкой. Такой вариант теплоотвода определяется большой величиной удельной выходной мощности GaN HEMT-транзисторов и оказывается обязательным даже с учетом того, что теплопроводность $\mathrm{GaN}$, как минимум, в пять раз больше, чем теплопроводность GaAs.

\section{Результаты расчетов}

На рис. 1, $a, b$ показаны фотография и схематический рисунок упрощенного продольного разреза мощного СВЧ НЕМТ-транзистора. Структура транзистора сформирована на GaAs-подложке, в каждой секции транзистора длины затворов равны $0.25 \mu \mathrm{m}$, активная область представляет собой встречно-штыревую структуру. На 
рис. 1, с схематично изображен тепловой интерфейс в виде диэлектрического покрытия толщиной $h_{C}$, обладающего высокой теплопроводностью (далее в расчетах $1000 \mathrm{~W} /(\mathrm{m} \cdot \mathrm{K}))$. Тепловой интерфейс сформирован на всей поверхности кристалла транзистора (вся область фото на рис. $1, a)$.

Компьютерное моделирование тепловых потоков и расчеты тепловых режимов работы транзистора были проведены для двух вариантов реальных мощных СВЧ НЕМТ-транзисторов, имеющих следующие конструктивные параметры.

A. Толщина GaAs подложки равна $100 \mu \mathrm{m}$, период секции (расстояние между затворами) составляет $28 \mu \mathrm{m}$. На нижней стороне подложки находятся слой гальванического золота толщиной $5 \mu \mathrm{m}$ и слой припоя $\mathrm{Sn}-\mathrm{Au}$ толщиной $20 \mu \mathrm{m}$.

Б. Толщина GaAs подложки равна $25 \mu \mathrm{m}$, период секции (расстояние между затворами) составляет $14 \mu \mathrm{m}$. На нижней стороне подложки, находится слой гальванического золота толщиной $30 \mu \mathrm{m}$ (интегральный теплоотвод) и слой припоя $\mathrm{Sn}-\mathrm{Au}$ толщиной $20 \mu \mathrm{m}$.

Численное моделирование было проведено для нескольких вариантов конструкции транзисторов: длина секций („пальцев“ ${ }^{6}$ затвора составляла 50 и $100 \mu \mathrm{m}$ при суммарной (по всем секциям) ширине затвора 1.2 и $2.4 \mathrm{~mm}$. Соответственно при одинаковой удельной мощности полная выходная мощность транзистора во втором случае будет в два раза больше, чем в первом случае. В процессе численного моделирования было принято, что зоны тепловыделения в каждой секции находятся в области между затворами и стоками вплотную к стоковым краям затворов, их ширина $0.3 \mu \mathrm{m}$, толщина $0.1 \mu \mathrm{m}$ (на рис. 1 затворы не показаны). Толщина металлизации контактных площадок истока и стока задавалась равной $2 \mu \mathrm{m}$.

Теплопроводность арсенида галлия считалась температурно-зависимой. Поскольку теплопроводность гальванического золота точно неизвестна, особенно после взаимодействия с припоем, она и теплопроводность припоя полагались равными $200 \mathrm{~W} /(\mathrm{m} \cdot \mathrm{K})$. Были проведены и расчеты при различных значениях теплопроводности золота в пределах $100-300 \mathrm{~W} /(\mathrm{m} \cdot \mathrm{K})$. В результате было выяснено, что такая вариация значений теплопроводности золота приводит к незначительному (на несколько процентов) изменению температуры канала, что совершенно не оказывает влияния на основные результаты работы. Теплопроводность диэлектрического слоя поверхностного теплового интерфейса была принята равной $1000 \mathrm{~W} /(\mathrm{m} \cdot \mathrm{K})$, что соответствует поликристаллическому АПП.

На рис. 2, 3 представлены результаты численного моделирования зависимости максимальной температуры в канале от удельной мощности тепловыделения транзистора для различных вариантов его исполнения. Расчеты были проведены для нескольких значений толщины теплоотводящего покрытия $h_{C}$. Из рисунка
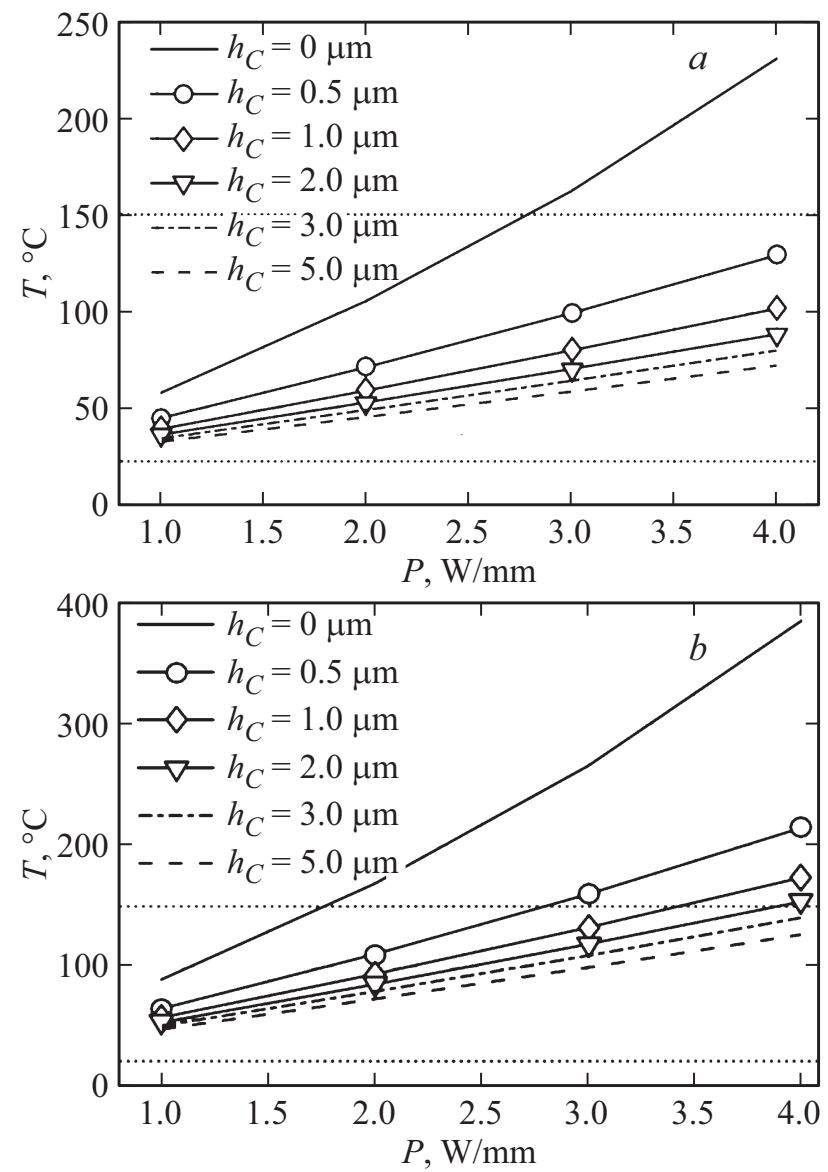

Рис. 2. Зависимость максимальной температуры в канале транзистора от удельной мощности тепловыделения. Горизонтальная верхняя пунктирная линия - критическая температура, выше которой начинаются процессы деградации, нижняя горизонтальная пунктирная линия - температура окружающей среды. Длина секций: $50(a), 100 \mu \mathrm{m}(b)$, толщина подложки $100 \mu \mathrm{m}$, период секций затворов $28 \mu \mathrm{m}$.

видно, что создание теплового интерфейса даже минимальной толщины приводит к значительному снижению температуры в канале транзистора. Уже при толщине теплоотводящего покрытия $0.5 \mu \mathrm{m}$ перегрев канала (относительно корпуса) уменьшается в $1.5-2$ раза, а увеличение этой толщины позволяет снизить перегрев канала транзистора в 2-4 раза. Количественное уменьшение величины перегрева канала, естественно, зависит и от топологических размеров прибора и от толщины подложки, однако во всех случаях нанесение теплопроводящего покрытия приводит к значительному снижению температуры канала. Особо следует отметить, что уменьшение длины секций позволяет значительно уменьшить величину максимального перегрева канала так же, как и для транзистора без алмазоподобного теплового интерфейса.

Эффект снижения перегрева был получен и при расчетах с теплоотводящими покрытиями, имеющими меньший коэффициент теплопроводности. В этих случа- 

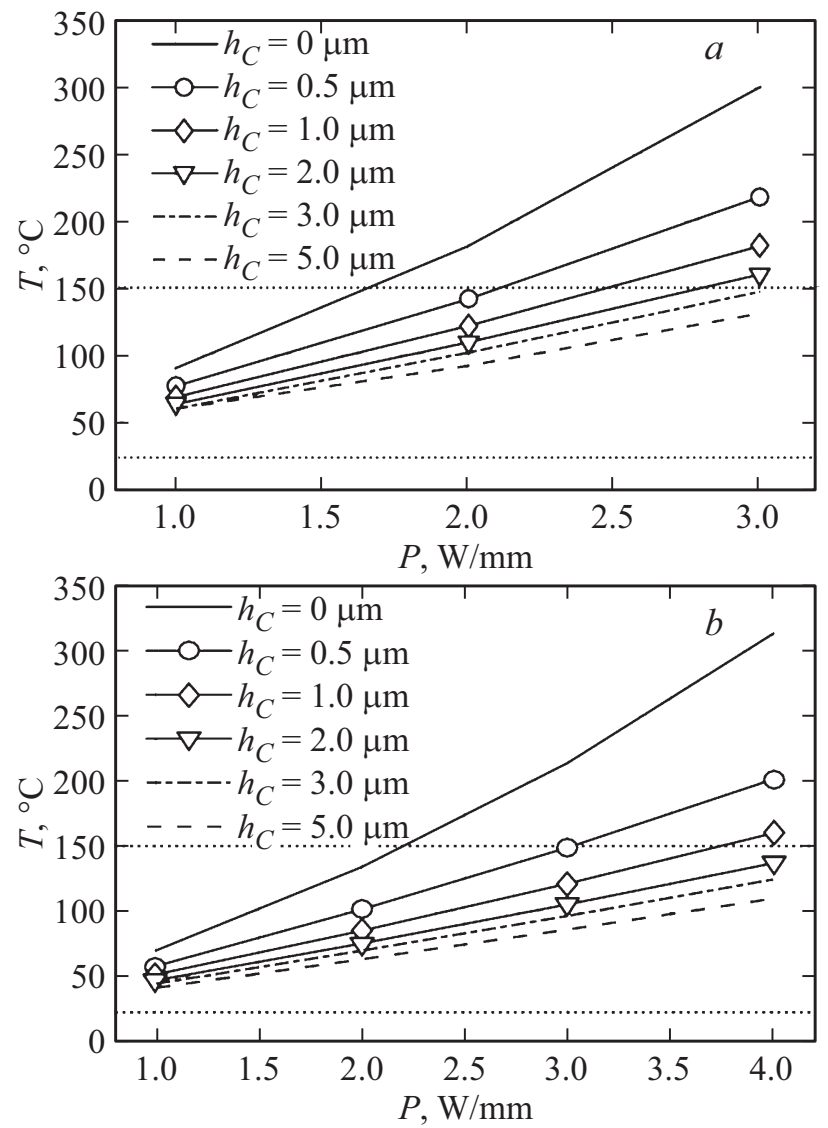

Рис. 3. Зависимость максимальной температуры в канале транзистора от удельной мощности тепловыделения. Горизонтальная верхняя пунктирная линия - критическая температура, выше которой начинаются процессы деградации, нижняя горизонтальная пунктирная линия - температура окружающей среды. Длины секций: $50(a), 100 \mu \mathrm{m}(b)$, толщина подложки: $25 \mu \mathrm{m}$ при слое гальванического золота толщиной $30 \mu \mathrm{m}$ и слое припоя $\mathrm{SnAu}$ толщиной $20 \mu \mathrm{m}$, период секций затворов $14 \mu \mathrm{m}$.

ях для сохранения малой величины теплового сопротивления интерфейса нужно просто увеличить его толщину. Естественно, при приближении теплопроводности теплового интерфейса к теплопроводности арсенида галлия, начинают появляться определенные особенности как в распределениях тепловых полей, так и в численных значениях температуры перегрева. Величина перегрева начинает расти, однако качественный эффект положительного влияния теплового интерфейса остается.

Исходя из полученных результатов на первый взгляд весьма перспективным представляется метод холодного нанесения на поверхность чипа транзистора, хорошо проводящего тепло $(50 \mathrm{~W} /(\mathrm{m} \cdot \mathrm{K})$ и более) лака или клея - изолятора после монтажа транзистора на теплоотводящее основание корпуса. Особая привлекательность этого метода заключается в том, что можно не заботиться о соответствии коэффициентов теплового расширения покрытия и арсенида галлия: пайка прибора уже прошла, а в процессе эксплуатации благодаря тепловому интерфейсу транзистор практически не нагревается.

Как показали оценочные электродинамические расчеты, нанесение теплоотводящего покрытия практически не изменяет параметры эквивалентной схемы транзистора. Следовательно, мощный гибридный усилитель может быть настроен в условиях слабого перегрева (например, в импульсном режиме с высокой скважностью и короткими импульсами). Затем на транзисторы наносится теплопроводящее покрытие, и прибор будет успешно работать в гораздо более жестких условиях - например, в непрерывном режиме и при высокой температуре окружающей среды. Дополнительное согласование транзистора в этом случае не понадобится.

Однако, к сожалению, в настоящее время номенклатура клеев с минимально подходящей теплопроводностью $(50-80 \mathrm{~W} /(\mathrm{m} \cdot \mathrm{K}))$ представлена клеями в основном с серебряными наполнителями. Такие клеи являются хорошими проводниками и поэтому не могут использоваться для наших целей. Возможна также проблема, состоящая в том, что толстый слой клея в результате усадки после высыхания может повредить затвор транзистора. Решением задачи может стать создание клеев с новыми нанокомпозитными наполнителями, разработка методов низкотемпературного нанесения АПП, или любых других покрытий с высокой теплопроводностью, совмещаемых с арсенид-галлиевыми технологиями, например, на основе уже существующих в настоящее время низкотемпературных методов [13,14].

Из приведенных на рис. 2, 3 результатов следует, что для рассматриваемых конструкций транзисторов при их эксплуатации в непрерывном режиме при комнатной температуре введение достаточно толстого $(\approx 2 \mu \mathrm{m})$ АПП практически решает проблему отвода тепла вплоть до удельных мощностей порядка $4 \mathrm{~W} / \mathrm{mm}$. Однако в различных видах оборудования, в том числе и специального назначения, транзисторы работают в гораздо более жестких условиях. Проведенные расчеты позволили сделать следующие выводы.

1. При работе транзисторов (период структуры $28 \mu \mathrm{m}$, толщина подложки $100 \mu \mathrm{m})$ в жестких условиях эксплуатации (непрерывный режим, температура окружающей среды $80^{\circ} \mathrm{C}$ ) тепловой интерфейс толщиной более $5 \mu \mathrm{m}$ с удельной теплопроводностью $1000 \mathrm{~W} /(\mathrm{m} \cdot \mathrm{K})$ позволяет решить проблему теплоотвода при удельной мощности тепловыделения менее $3.5 \mathrm{~W} / \mathrm{mm}$ для транзисторов с длиной секций $50 \mu \mathrm{m}$ и при удельной мощности тепловыделения менее $2.5 \mathrm{~W} / \mathrm{mm}$ для транзисторов с длиной секций $100 \mu \mathrm{m}$.

2. Если транзистор имеет период структуры $14 \mu \mathrm{m}$, толщину подложки $25 \mu \mathrm{m}$, то тепловой интерфейс толщиной более $5 \mu \mathrm{m}$ и теплопроводностью $1000 \mathrm{~W} /(\mathrm{m} \cdot \mathrm{K})$ позволяет решить проблему теплоотвода при удельной мощности тепловыделения менее $2 \mathrm{~W} / \mathrm{mm}$ для транзисторов с длиной секций $50 \mu \mathrm{m}$ и при удельной мощности тепловыделения менее $1.5 \mathrm{~W} / \mathrm{mm}$ для транзисторов с 
длиной секций $100 \mu \mathrm{m}$. Транзистор работает в непрерывном режиме и температуре окружающей среды $80^{\circ} \mathrm{C}$.

При анализе графиков на рис. 2, 3 видно, что в случае использования теплового интерфейса большой толщины, максимальные температуры каналов в рассматриваемых конструкциях отличаются незначительно при одинаковых плотностях мощности. Расчеты показывают, что уменьшение толщины подложки с 100 до $25 \mu$ m уменьшает тепловое сопротивление примерно в 2 раза, а уменьшение вдвое расстояния между секциями затворов примерно в 2 раза увеличивает перегрев. Эти оценки проведены с учетом припоя и интегрального теплоотвода (слоя гальванического золота порядка $30 \mu \mathrm{m}$ на подложке). Именно это обстоятельство и определяет „похожесть“ графиков на рис. 2,3.

Как отмечалось ранее, для продвижения в область коротковолновой части сантиметрового и в миллиметровый диапазон длин волн необходимо увеличивать плотность упаковки элементов транзистора (уменьшать расстояния между затворами и секциями транзистора). Это справедливо как для транзисторов, так и для монолитных усилителей мощности. Причем если технология монтажа отдельных транзисторов с подложкой толщиной $25 \mu \mathrm{m}$ и интегральным теплоотводом достаточно отработана на ряде предприятий [15], то для монолитных усилителей это является определенной проблемой, поскольку усилитель имеет большие, по сравнению с транзистором, размеры. Из полученных результатов следует, что если применить тепловой интерфейс, то транзисторы с плотной упаковкой можно использовать в монолитных усилителях с более толстыми (порядка $100 \mu \mathrm{m})$ подложками, что значительно упрощает технологию монтажа таких приборов в корпус. Наиболее актуальным этот метод выглядит для усилителей мощности, содержащих несколько мощных транзисторов. Введение поверхностного теплового интерфейса позволяет повысить выходную мощность усилителя при плотной упаковке транзистора без значительного утонения подложки. Важным представляется и то обстоятельство, что введение поверхностного теплового интерфейса не требует изменения технологии изготовления мощных полевых транзисторов и монолитных усилителей.

\section{Анализ физических эффектов}

Столь резкое уменьшение перегрева при введении теплового интерфейса по сути дела означает, что при достаточно толстом теплопроводящем покрытии дополнительный поток тепла от транзистора отводится вверх, далее в стороны на периферию кристалла транзистора, затем вниз через подложку в корпус. Действительно, даже если рассмотреть абсолютно симметричную задачу - всю структуру зеркально отобразить относительно верхней поверхности транзистора, а мощность тепловыделения оставить прежней, то величина перегрева канала уменьшится в 2 раза. Однако использование в

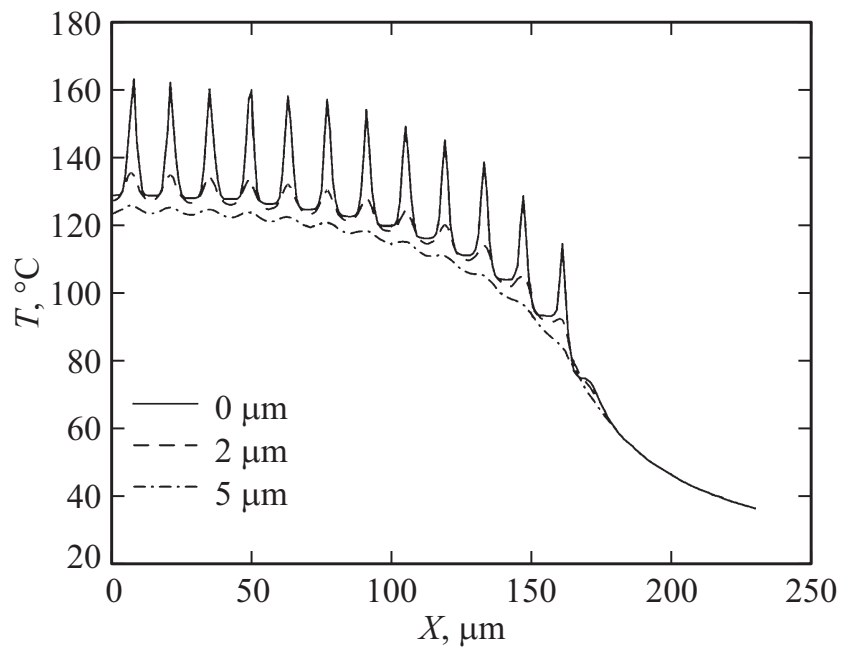

Рис. 4. Распределение температуры в транзисторной структуре без поверхностного теплового интерфейса в сечении, перпендикулярном секциям затворов. Отсчет координаты ведется от центра транзисторной структуры. (-) - температура на поверхности, (-- - ) - на глубине $2 \mu \mathrm{m}$, $(-\cdot-\cdot-)$ на глубине $5 \mu \mathrm{m}$. Температура корпуса $23^{\circ} \mathrm{C}$. Толщина GaAs-подложки $100 \mu \mathrm{m}$. Удельная мощность тепловыделения $1 \mathrm{~W} / \mathrm{mm}$.

тепловом интерфейсе материала, имеющего теплопроводность на порядок большую, чем GaAs и ряд специфичных „транзисторных“ особенностей, приводит к ряду дополнительных эффектов. Дело в том, что области тепловыделения в секциях НЕМТ-транзистора жестко локализованы, имеют малые размеры, что приводит к сильной неоднородности распределения температуры по поверхности кристалла в направлении длины канала [4]. Расчеты, проведенные нами (рис. 4), показали, что на поверхности кристалла в области локального тепловыделения перегрев относительно соседних областей на расстоянии в несколько микрон составляет более $25 \%$ $\left(\sim 30^{\circ} \mathrm{C}\right)$, тогда как на глубине в несколько микрон этот разброс температур уменьшается во много раз. Кроме того, ширина затвора в одиночной секции транзистора (длина „пальца“) сравнима по размерам с толщиной подложки, что приводит к сильному изменению температуры (до 1.5 раз) и по длине секции. То есть на поверхности активной области транзистора температурные поля сильно неоднородны как в продольном, так и поперечном направлении по отношению к ориентации одиночной секции затвора. Поэтому даже если нанести теплопроводящее покрытие только на активную область прибора (на прямоугольник, ограниченный крайними секциями и шириной затвора), то тепло отведется из области локального тепловыделения вверх и распределится по площади покрытия. Это распределение тепла сглаживает перепады температуры в направлении и длин каналов, и секций (рис. 5). Поток тепла вниз в этом случае станет более однородным по всей поверхности. Поэтому на рис. 5 соответствующая кривая не 


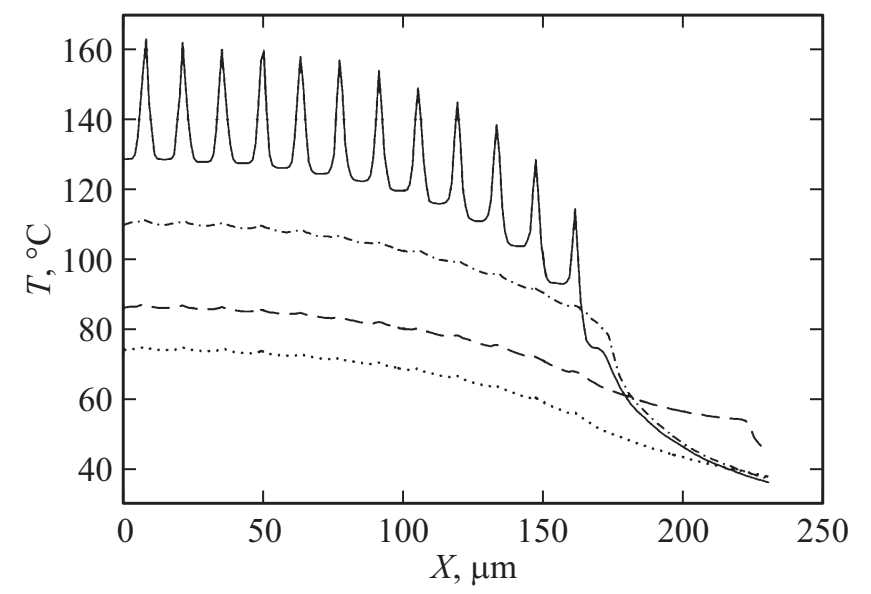

Рис. 5. Распределение температуры в транзисторной структуре в сечении, перпендикулярном секциям затворов. Отсчет координаты ведется от центра транзисторной структуры. Температура корпуса $23^{\circ} \mathrm{C}$. Мощность тепловыделения $1 \mathrm{~W} / \mathrm{mm}$, длина секции $100 \mu \mathrm{m}$, толщина подложки $100 \mu \mathrm{m}$, температура основания: $23^{\circ} \mathrm{C}$. (-) - результаты расчета при отсутствии теплового интерфейса (верхняя кривая). Тепловым интерфейсом толщиной $2 \mu \mathrm{m}$ покрыты: $(-\cdot-\cdot-)-$ только активная область транзистора, $(----)-$ активная область транзистора и периферия поверхности чипа вокруг активной области на расстоянии $50 \mu \mathrm{m},(\ldots \ldots)-$ вся поверхность чипа (нижняя кривая).

только более гладкая, но и проходит заметно ниже, чем минимальные значения температуры в транзисторах без интерфейса. Расширение покрытия на $50 \mu \mathrm{m}$ за активную область транзистора приводит к увеличению площади, через которую тепло активно уходит в корпус, и к дополнительному достаточно сильному уменьшению температуры. Еще более сильное расширение теплового интерфейса - на всю площадь чипа - приводит к дальнейшему (хотя и к относительно меньшему) падению температуры. Из этих результатов расчетов можно сделать вывод, что вклады механизма сглаживания температуры на поверхности, и механизма отвода тепла через интерфейс в стороны, а затем в подложку, сравнимы. Совокупное действие этих механизмов при достаточно толстом тепловом интерфейсе уменьшает перегрев транзистора в несколько раз.

\section{Заключение}

Теоретически исследованы возможности использования теплопроводящих покрытий для охлаждения мощных НЕМТ-транзисторов. Показано, что в зависимости от толщины покрытия, конструкции транзистора и режима его работы, перегрев канала можно снизить в несколько раз. Это обусловлено как выравниванием температуры по всей активной области транзистора, так и высокой эффективностью отвода тепла вверх (в тепловой интерфейс) и в стороны (по тепловому интерфейсу) от локальных областей интенсивного тепловыделения с передачей тепла по всей площади транзисторного чипа через подложку в корпус. Показано, что тепловой интерфейс, имеющий теплопроводность ниже, чем у поликристаллического алмаза, но существенно выше, чем у GaAs, оказывает аналогичное влияние, если его толщину увеличить пропорционально снижению теплопроводности. Продемонстрировано, что введение теплопроводящего покрытия позволяет значительно уменьшить величину перегрева канала относительно корпуса. Таким образом, эффективность теплоотвода повышается без дополнительных мер по уменьшению теплового сопротивления подложки при сохранении базовой технологии изготовления транзисторов.

Продемонстрировано, что при использовании теплового интерфейса транзисторы с плотной упаковкой (с топологией, предусматривающей использование подложек толщиной порядка $25 \mu \mathrm{m})$ могут успешно работать при толстых (порядка $100 \mu \mathrm{m})$ подложках. Таким образом, формирование теплового интерфейса может оказаться особенно перспективным для монолитных усилителей мощности на толстых подложках, позволяющих упростить технологию монтажа приборов на основание.

\section{Список литературы}

[1] Лукашин В.М., Пашковский А.Б., Журавлев К.С., Торопов А.И., Лапин В.Г., Соколов А.Б. // Письма в ЖТФ. 2012. Т. 38. Вып. 17. С. 84-89.

[2] Журавлев К.С., Лапин В.Г., Лукашин В.М., Пашковский А.Б., Соколов А.Б., Торопов А.И. // Электронная техника. Сер. 1. СВЧ-техника. 2012. Вып. 1. № 512. C. $55-61$.

[3] Лукашин В.М., Пашковский А.Б., Журавлев К.С., Торопов А.И., Лапин В.Г., Голант Е.И., Капралова А.А. // ФТП. 2014. Т. 48. Вып. 5. С. 684-692.

[4] Воробьев А.А., Галдецкий А.В. // Электронная техника. Cер. 1. СВЧ-техника. 2011. Вып. 3. № 510. С. 42-54.

[5] Chao P.C. et al. // MRS Advances. 2016. Vol. 1. N 2. P. $147-155$.

[6] Chao P.C. et al. // CS MANTECH Conf. Digest. 2013. P. $179-182$.

[7] Altman D. // Raytheon Technol. Today. 2012. N 1. P. 18.

[8] Дудинов К.В., Ипполитов В.М., Пашковский А.Б. // Электронная техника, Сер. 1. СВЧ-техника. 2006. Вып. 2. № 488. C. 5-7.

[9] Бережнова П.В., Лукашин В.М., Ратникова А.К., Пашковский А.Б. // Электронная техника. Сер. 1. СВЧ-техника. 2007. Вып. 4. № 492. С. 21-24.

[10] Воробьев А.А., Воробьева Е.В., Галдечкий А.В. // Электронная техника. Сер. 1. СВЧ-техника. 2011. Вып. 3. № 510. C. $37-41$.

[11] IEEE Electron Device Letters, 2014. Vol. 35. N 10. P. 1013-1015.

[12] MORGaN final brochure Nov-2011.

[13] Гиппиус А.А. и др. Патент № 2244983 C1 (RU) от 14.07.2003.

[14] Seok $O$. et al. // CS MANTECH Conf. May 17th-20th, 2010, Portland, Oregon, USA, P. 229-231.

[15] Королев А.Н., Климова А.В., Красник В.А., Ляпин Л.В., Малыщик В.М., Манченко Л.В., Пчелин В.А., Трегубов В.Б. // Радиотехника. 2007. № 3. С. 53-56. 